\title{
Sobre a constituição da disciplina curricular de língua portuguesa*
}

\author{
Émerson de Pietri
}

Universidade de São Paulo, Faculdade de Educação

\section{Introdução}

A década de 1970, no Brasil, caracteriza-se pela ampliação das possibilidades de acesso ao ensino formal e pelo aumento, de quatro para oito, do número de anos de escolarização básica. ${ }^{1}$ As mudanças curriculares se acompanham da publicação de documentos que teriam o objetivo de subsidiar a implementação de uma nova concepção de escolarização e de ensino.

A leitura de documentos produzidos à época e de documentos que tomam os fatos de então como objeto de análise e/ou discussão evidencia a existência de certa dissonância nas interpretações - possibilitada pelo próprio texto da legislação que alterava a ordem do sistema escolar-, tanto em relação aos princípios da concepção curricular para o ensino de $1^{\circ}$ grau quanto para a constituição das disciplinas que comporiam o currículo proposto.

\footnotetext{
${ }^{*}$ Neste artigo apresentam-se resultados de pesquisa financiada pelo CNPq.

${ }^{1} \mathrm{O}$ exame de admissão para a passagem do grupo escolar ao ginásio foi extinto em 1971, estabelecendo-se a ordenação de 1a a $8^{\underline{a}}$ séries, que comporia o então denominado $1^{\circ}$ grau.
}

Em meio a essas diversas interpretações e suas dissonâncias, encontra-se a situação da disciplina língua portuguesa em relação aos modos de sua constituição interna e de sua composição na estrutura curricular.

As diferenças de interpretação e de compreensão do texto da lei n. 5.692/71, que fixava as diretrizes e bases para o ensino de $1^{\circ}$ e $2 \stackrel{\circ}{\circ}$ graus, refletiram-se de diferentes maneiras na elaboração dos guias referenciais para o ensino e na produção de materiais didáticos.

Some-se o fato de que a recepção da lei em questão se fez em meio à ausência de estrutura material e física para acomodar a nova ordem; em meio à falta de recursos econômicos e humanos para implementar as mudanças e realizar as novidades propostas; e em condições contraditórias, que possibilitavam apropriações e resistências diversas. ${ }^{2}$

Neste trabalho, pretende-se problematizar algumas considerações sobre o período - a década de 1970

${ }^{2}$ Considere-se que as proposições para o ensino, elaboradas segundo princípios considerados democráticos e de liberdade para a escola, circulavam em documentos produzidos e publicados pelo estado, sob regime de ditadura militar. 
no Brasil - em relação aos modos de organização curricular do ensino e, em específico, às características que teria adquirido a disciplina língua portuguesa nesse momento de seu processo de constituição histórica. Problematizam-se, assim, as considerações quanto à identidade da disciplina, à sua inserção curricular e à sua função pedagógica, o que insere as considerações realizadas no presente trabalho em diálogos próprios à história das disciplinas escolares.

São apontadas por Soares (2002) como características principais dessa disciplina curricular, no período, o fato de ter sido alterada sua denominação - não mais língua portuguesa, mas comunicação e expressão; de ter como base, para sua estruturação interna, a teoria da comunicação -, minimizando-se, em relação aos conteúdos, os conhecimentos próprios ao ensino gramatical tradicional (o que caracterizaria, inclusive, um hiato em relação ao que anteriormente constituía essa disciplina); e de ter como objetivo formar cidadãos instrumentalizados para o mercado de trabalho, aptos para as exigências que o desenvolvimento econômico apresentaria, o que teria conferido caráter pragmático à disciplina.

É preciso considerar, no entanto, que essas características são parte de uma ordem mais complexa, em que compõem, junto a várias outras, um conjunto que se constitui pela diversidade de tendências, pela conjunção de forças distintas que se somavam ou se opunham, pela difusão (ou, por vezes, confusão) de sentidos em concorrência.

Tal situação não seria decorrente apenas das lutas e resistências contra a imposição de uma determinada ordem pelo poder instituído, mas também, ou talvez principalmente, pela ausência de um programa bem organizado, de um projeto coerente com as condições de sua realização.

\section{A constituição histórica da disciplina língua portuguesa}

As considerações acerca do processo de constituição da disciplina língua portuguesa realizar-se-ão segundo perspectivas desenvolvidas no interior do campo de estudos a que se convencionou denominar história das disciplinas escolares, ${ }^{3}$ caracterizado por considerar, segundo novos princípios, a historiografia da educação. Para a história das disciplinas, não se privilegiam as narrativas sobre ideias e discursos pedagógicos, mas colocam-se como relevantes para o trabalho do pesquisador os elementos que compõem a constituição dos saberes e as práticas escolares e os modos dessa constituição (ver Bittencourt, 2003).

O espaço e o tempo da escola são então considerados em sua complexidade, e novos materiais apresentam-se ao analista para a compreensão dos processos de emergência e desenvolvimento das disciplinas. Tomadas em sua dimensão social e histórica, as disciplinas curriculares são compreendidas não apenas como instâncias de transposição didática de conhecimentos produzidos pelas ciências de referência (Chevallard, 1985), mas como campo autônomo em que concorrem agentes e elementos internos e externos e em que não apenas se reproduzem ou divulgam ideias, em que se produzem saberes e práticas próprios, que compõem a cultura escolar (Chervel, 1990).

A pesquisa nesse campo se realiza, assim, de modo que construa procedimentos que exponham o analista a sentidos não acessíveis de forma direta ou de modo evidente à interpretação. ${ }^{4}$ Como relata Gatti

${ }^{3}$ Souza Júnior e Galvão (2005) afirmam remeter ao mesmo campo de pesquisa as denominações: história das disciplinas escolares, história das disciplinas curriculares, história das matérias escolares, história dos saberes escolares, história dos conteúdos escolares. Opta-se aqui por referir o campo por "história das disciplinas escolares", devido a que outras denominações possam estar associadas a discussões a respeito do caráter das disciplinas ou matérias, segundo sejam concebidas enquanto instâncias de transposição didática ou instâncias próprias às elaborações da cultura escolar; objetiva-se, assim, evitar confusões quando das discussões a serem realizadas, na sequência do artigo, sobre o lugar da disciplina língua portuguesa nas propostas de reorganização curricular realizadas no momento histórico observado, dado que termos como disciplina, matéria e área de estudo se referem a diferentes ordens nas propostas de reorganização curricular de então.

${ }^{4}$ Nesse sentido, é possível agenciar elementos de análise do discurso para o trabalho com os dados. Nos dizeres de Maingueneau 
Jr. (2009, p. 45), dessa mudança nos modos de se realizar o trabalho historiográfico, novas possibilidades metodológicas produziram-se, inseridas num fazer analítico com ênfase não no produto das reflexões, mas no processo de investigação:

Em termos epistemológicos, o que parece estar em jogo aqui não é a atribuição à razão, ao método ou mesmo às fontes de pesquisa do critério de validade dos conhecimentos científicos alcançados, mas sim a qualidade do diálogo estabelecido pelo pesquisador/historiador entre teorias, métodos e evidências na efetivação de seu processo de investigação, o que não aparece de antemão, mas sim nos resultados apresentados.

Nessa mudança epistemológica, as fontes de pesquisa ampliaram-se, de modo que possibilitaram a elaboração de maior variedade de relações entre instâncias enunciativas e processos de interpretação. É o que depreende Gatti Jr. (idem, p. 68), ao observar os estudos sobre história de uma disciplina específica:

Da análise dessa historiografia sobre a história do ensino de História mais recente, depreende-se a existência de uma hermenêutica que comporta a recusa de tratar a temática da disciplina escolar de modo prescritivo e a-histórico, o esforço em abordar a temática de modo compreensivo e, por fim, a busca da compreensão dos usos sociais das disciplinas nos diferentes níveis de ensino.

Ao lado dessa constatação, pode ser percebido o desenvolvimento de uma heurística da história das disciplinas escolares, na qual os historiadores trabalham com variadas fontes e evidências de pesquisa, tais como as mais comumente

(1989, p. 11), "O analista do discurso vem, dessa forma, trazer sua contribuição às hermenêuticas contemporâneas. Como todo hermeneuta, ele supõe que um sentido oculto deve ser captado, o qual, sem uma técnica apropriada, permanece inacessível. [...] Entretanto, como lembra M. Pêcheux, a análise de discurso não pretende se instituir como especialista da interpretação, dominando 'o' sentido dos textos; apenas pretende construir procedimentos que exponham o olhar-leitor a níveis opacos à ação estratégica de um sujeito". apresentadas nas investigações neste campo: bibliografia variada, documentos impressos e manuscritos, depoimentos orais e iconografia.

Conclui-se que a renovação advinda da virada antropológica no campo da História e da História da Educação possibilitou o estabelecimento, em melhores bases, de uma compreensão da dialética existente na relação entre a particularidade das atividades desenvolvidas pelos indivíduos nas escolas e o que se passa de modo mais geral na sociedade.

As novas possibilidades epistemológicas encontradas no campo da história das disciplinas incluem, assim, o trabalho segundo perspectiva historiográfica em que as análises de documentos escritos fornecem dados e evidências - e o trabalho segundo perspectiva de caráter sociológico - em que se produzem dados a partir das vozes dos sujeitos em entrevistas e histórias de vida (Goodson, 2005).

No presente trabalho, a investigação volta-se especificamente à análise de documentos escritos, de modo que observem a complexidade dos processos de constituição da disciplina língua portuguesa em documentos oficiais. Considera-se que, mesmo em relação aos fatores externos atuantes sobre o processo de constituição das disciplinas, e, dentre eles, aqueles supostamente mais controlados quanto às possibilidades de produção de sentidos, também se fazem em arenas com regras próprias de operação dos sujeitos, o que implica reposicionamentos para agentes envolvidos no processo de construção do currículo e para concepções de linguagem e de ensino agenciadas na elaboração dos documentos. ${ }^{5}$

Os documentos que compõem o corpus do presente trabalho serão analisados com o objetivo de perceber as diferentes tensões que se estabelecem pela aproximação de perspectivas distintas para a concepção de uma proposta curricular. Nesse sentido, os seus diálogos constituintes nem sempre se produzem como um discurso homogêneo (ainda que a expectativa quanto a um documento oficial de referência curri-

${ }^{5}$ Sobre a discussão a respeito de elaboração curricular e reposicionamento, conferir Goodson (2006, p. 31 ss.). 
cular possa ser essa), mas evidenciam dissonâncias, incompatibilidades e contraposições resultantes da aproximação de perspectivas epistemológicas distintas, por vezes incompatíveis, e de suas relações com projetos políticos e as funções que se atribuem para a escolarização.

Goodson (idem, p. 27), em referência ao trabalho de Hobsbawm e Ranger (1984), considera que "a elaboração de currículo pode ser considerada um processo pelo qual se inventa uma tradição"; nesse processo, a elaboração do currículo escrito seria "o exemplo perfeito" de tal invenção. No entanto, o autor afirma que se trata não de algo pronto de uma vez por todas, mas de algo "antes, a ser defendido onde, com o tempo, as mistificações tendem a se construir e reconstruir".

Ao observar os documentos curriculares que compõem o material de análise do presente trabalho, procura-se evidenciar as tensões entre tradição e inovação como fator estruturante do próprio discurso de que o documento curricular observado é a materialização textual. A relação polêmica entre discursos seria, assim, não decorrência da invenção de uma nova tradição, mas sua própria possibilidade de existência, pois constitutiva do processo interdiscursivo que se estabelece. $^{6}$

\section{A disciplina língua portuguesa: do período colonial à década de 1960}

Segundo Soares (idem), a disciplina língua portuguesa tem sua inclusão tardia no currículo escolar brasileiro, o que ocorreu nas últimas décadas do século XIX. Até esse momento, um longo percurso fez-se para que a língua portuguesa se constituísse em objeto e objetivo de ensino.

${ }^{6} \mathrm{O}$ termo polêmica é compreendido aqui de acordo com a noção de interdiscurso proposta por Maingueneau (2005). De acordo com o autor (idem, p. 23), a interdiscursividade constituise como uma situação de delimitação recíproca entre discursos, fundamentada em relação polêmica. Concebido o sistema de restrições como um modelo de competência discursiva, considera-se
No Brasil colonial, aponta a autora, conviviam o português, a língua geral (prevalente no cotidiano e provinda de línguas do tronco tupi) e o latim. O português era aprendido na escola não como componente curricular, mas como instrumento para a alfabetização. Desta passava-se direto ao latim, que fundamentava as práticas, no ensino secundário e superior, para o estudo da gramática latina e da retórica (com base em autores latinos e em Aristóteles).

Até o século XVII, apesar da produção de gramáticas e dicionários, o português ainda não se constituíra em área de conhecimento em condições de gerar uma disciplina curricular, o que também decorria de seu pouco uso no intercurso verbal e de seu pouco valor como bem cultural.

Na segunda metade do século XVIII, as reformas pombalinas, com o objetivo de garantir o poder sobre as colônias, intervêm nas condições de constituição da disciplina, ao tornar obrigatório o uso da língua portuguesa no Brasil e proibir o uso de outras línguas. Porém, tal como concebido pela reforma, o objetivo de saber ler e escrever em português, bem como de conhecer sua gramática, tinha ainda caráter instrumental, isto é, tornar possível o aprendizado da gramática latina.

Ainda segundo Soares (idem), gramática e retórica prevaleceram do século XVI ao século XIX na área de estudos da língua. A retórica, no período em questão, passou a ser progressivamente estudada também em autores da língua portuguesa e incluiu, inicialmente, a poética, que depois se tornou componente curricular independente.

Como informa a autora, durante as primeiras quatro décadas do século XX, com a progressiva perda do valor do ensino de latim, assumiu autonomia o ensino da gramática do português. A retórica também sofre modificações no período, quando se substituiu, como objetivo da disciplina, o falar bem, algo já não

que os enunciadores de um discurso dado apresentam o "domínio tácito de regras que permitem produzir e interpretar enunciados que resultam de sua própria formação discursiva e, correlativamente, permitem identificar como incompatíveis com ela os enunciados das formações discursivas antagonistas". 
tão valorizado socialmente, pelo escrever bem, então exigência social.

A partir dos anos 1950, começou a ocorrer real modificação no conteúdo da disciplina língua portuguesa, em função da progressiva transformação nas condições sociais e culturais e das possibilidades de acesso à escola, o que exigiu reformulação das funções e objetivos dessa instituição.

Teria se iniciado, a partir de então, a modificação das características do alunado, em razão da democratização do acesso à escola. A ampliação da oferta de escolarização teria promovido aumento da demanda por professores - nessa época, já formados em faculdades de filosofia -, o que teria implicado menor seletividade na contratação desses profissionais, e, em consequência, prejuízo para a qualidade de ensino.

Se até então, durante as quatro primeiras décadas do século XX, gramática e coletânea de textos constituíam dois materiais didáticos independentes, a partir da década de 1950, gramática e texto, estudo sobre a língua e estudo da língua começam, afirma Soares (idem), a constituir realmente uma disciplina com conteúdo articulado.

Desse modo, num processo que se inicia nos anos 1950 e se consolida na década de 1960, a fusão de gramática e livro de textos faz-se de forma progressiva, e os manuais passam a apresentar exercícios de vocabulário, de interpretação, de redação e de gramática. Estuda-se gramática a partir do texto e vice-versa, com primazia conferida àquela.

Nesse momento, em que começa a ser transferida ao livro didático (ao seu autor) a tarefa de preparar aulas e exercícios, teria se intensificado, segundo a autora, o processo de depreciação da função docente.

\section{A década de 1970}

Como visto, a democratização do acesso à escola, que se iniciou na década de 1950, produziu a necessidade de contratação de maior número de professores. A esse fator associam-se a necessidade de formação de professores em grande número para atender à demanda produzida; a implementação ainda recente dos cursos de letras nas faculdades de Filosofia; as mudanças no caráter interno da disciplina língua portuguesa, com a gramática adquirindo primazia em relação aos demais conteúdos da disciplina; e a dependência cada vez maior do professor em relação ao autor do livro didático.

Essas condições são amplificadas na década de 1970, quando, pela lei n. 5.692/71, o oferecimento de oito anos de escolarização passa a ser obrigatório.

Segundo Soares (idem), quando a ditadura militar intervém, nas décadas de 1960 e 1970, algumas mudanças importantes teriam sido operadas em relação ao ensino, em geral e ao ensino de língua portuguesa em particular. Assim, no período, segundo a autora, a educação foi colocada a serviço do que se nomeou desenvolvimento. $\mathrm{O}$ ensino teria assumido caráter pragmático e utilitarista, e seu objetivo seria o desenvolvimento do uso da língua, o que se conseguiria com alterações na disciplina, que se fundamentaria a partir de então em elementos da teoria da comunicação. Nesse novo contexto, o aluno seria visto como um emissor-receptor de códigos os mais diversos, e não mais apenas do verbal.

Ainda segundo a autora, a concepção de língua como sistema (ensino de gramática) e a concepção de língua como expressão estética (ensino da retórica $\mathrm{e}$ poética, e, posteriormente, estudo de textos) foram substituídas pela concepção de língua como comunicação.

A presença da gramática nos livros didáticos teria sido minimizada, surgindo a polêmica (que se mantém atual) quanto a ensinar ou não gramática.

Teria havido, também, a ampliação do conceito de leitura (não mais apenas voltada para a recepção do texto verbal, mas também do não verbal), e a escolha dos textos para uso no ensino não mais se faria exclusivamente segundo critérios literários, mas segundo a intensidade de sua presença nas práticas sociais.

Seria um momento, portanto, em que não se encontraria em plena vigência o que se convencionou denominar ensino tradicional, isto é, o ensino fundamentado numa variedade única da língua (a escrita, literária), representada na gramática normativa da língua portuguesa. 
O período em questão caracterizar-se-ia, em relação ao trabalho escolar com a linguagem, pela busca do desenvolvimento da modalidade oral, com objetivos de promover a capacidade de comunicação do indivíduo para sua inserção social, principalmente no campo do trabalho. Haveria, então, nesse momento histórico, um hiato na primazia conferida à gramática no ensino de português.

Segundo Soares (idem), essas mudanças permaneceriam até meados dos anos 1980, quando, com o processo de redemocratização do país, a disciplina voltaria a ser denominada português e teorias da área das ciências linguísticas, ainda que já previstas nos currículos de formação de professores desde a década de 1960, chegariam finalmente ao campo do ensino de língua materna.

\section{As mudanças no ensino fundamental, na década de 1970}

As informações apresentadas por Soares (idem) em relação às alterações na disciplina língua portuguesa na década de 1970 são pertinentes quando se consideram os fatos sem se fazer diferenciação de três diferentes aspectos em jogo naquele momento histórico.

De forma geral, o ensino de língua portuguesa parece ter apresentado, em determinadas instâncias, as características relatadas pela autora, como a alteração do nome da disciplina; as mudanças em seus conteúdos e objetivos; a ruptura em relação ao ensino tradicional, que se fundamentava no ensino de gramática. Porém, ao serem observados separadamente os fatores relativos ao didático, ao acadêmico e ao oficial, percebe-se que cada uma dessas três esferas contribuiu de modo diferenciado para o conjunto de forças existente no período em análise.

Em relação às proposições formuladas pelos órgãos oficiais para o ensino básico em sua estrutura curricular e as relações que se estabeleceram entre essas proposições e aquelas produzidas no meio acadêmico, o período caracteriza-se pela diversidade de perspectivas presentes, tanto teóricas quanto sociais e políticas. Tal diversidade se constituiu em função de o próprio momento histórico ser reconhecido por mudanças estruturais importantes, sem que houvesse muitas vezes o devido planejamento para sua realização.

\section{As alterações estruturais na escolarização básica}

A principal alteração proposta no período em relação à estruturação do ensino básico referiu-se ao aumento do tempo de escolarização obrigatória no ensino fundamental (de quatro para oito anos) e ao estabelecimento de continuidade de seriação entre os graus ( $1^{\circ}$ e $2^{\circ}$ ), o que contribuiu para o fim dos exames de admissão para aqueles que concluíam os quatro anos do grupo escolar e se dirigiam para perfazer os quatro anos do ginásio.

Essas alterações foram propostas pela lei n. 5.692/71, que previa tanto a ampliação do acesso ao ensino fundamental de oito anos quanto à reestruturação curricular com o objetivo de tornar possível a implementação dessas mudanças nos diferentes contextos socioeconômicos em que as escolas estariam inseridas.

Ainda que paradoxal, considerando-se o regime político instalado no momento histórico em que tais objetivos foram propostos, as alterações no currículo, de acordo com a lei n. 5.692/71, visavam a proporcionar ao professor liberdade para o planejamento de seu trabalho, de modo que pudesse elaborar a disciplina sob sua responsabilidade em função das características da comunidade em que se encontrasse a escola, e, portanto, em função dos alunos a quem a instituição atendia.

Nesse sentido, como apontam Silva e Arelano (1985), houve, por parte do grupo de trabalho que elaborou as diretrizes para a referida lei, o cuidado de garantir que a nova concepção curricular fosse implementada de modo que não anulassem o nível de autonomia que se procurava conferir ao professor e à escola.

Tal cuidado se mostra nas tentativas de possibilitar a adequação dos currículos aos diferentes contextos existentes na sociedade e, ao mesmo tempo, garantir 
um conjunto de conhecimentos comum a todas as escolas, de modo que possibilitassem a existência de um sistema de ensino minimamente homogêneo.

Essa preocupação esteve diretamente relacionada à própria interpretação do texto da lei: segundo ela, haveria uma recomposição curricular que implicaria, inclusive, a alteração dos sentidos tradicionalmente atribuídos a termos como matéria, disciplina e área de estudo. A alteração tinha como objetivo não mais fixar conteúdos e metodologia que compusessem um currículo obrigatório, mas deixar que professores e escolas construíssem o currículo em conformidade com as condições em que atuavam.

Assim, ainda segundo Silva e Arelano (idem), a disposição proposta pelo grupo de trabalho para a nova estrutura curricular previa que as atividades de ensino se iniciassem na atividade do aluno, que, considerada no interior de uma área de estudos, seria objeto de um início de sistematização, para, a seguir, localizar-se no interior de um conjunto de conhecimentos sistemáticos, a que se denominava disciplina. As autoras chamam a atenção para o fato de que o estabelecimento desse percurso já caracteriza um tipo de instrução metodológica a que o referido grupo de trabalho, a princípio, se colocara contrariamente.

A necessidade de estabelecer um conjunto de conhecimentos que compusesse um mínino obrigatório, somada às dificuldades de interpretação dos termos empregados no processo de reestruturação curricular, geraram impasses que se refletiram no ensino, de modo que produziram equívocos ou resistência.

\section{As alterações curriculares no ensino fundamental}

O fato de se considerar necessário o estabelecimento de um conjunto mínimo de conhecimentos comuns para o ensino em caráter nacional levou a que se produzisse um movimento contrário ao que primeiramente se propôs para a estruturação curricular. Nas palavras de Silva e Arelano (idem, p. 35): "percebe-se, sem dúvida, que, apesar de se reconhecer a necessidade de indicar 'disciplinas' obrigatórias e mesmo um conteúdo mínimo (programas) a ser desenvolvido, havia pruridos disto ser admitido no papel, como se isto ferisse a 'autonomia' dos sistemas estaduais de ensino".

As autoras chegam a referir a "aversão da lei por ditar normas" (idem), porém, ainda que houvesse tal aversão, a necessidade do currículo mínimo e a dificuldade imposta pela ressignificação dos termos no texto da lei levaram a que, na própria continuidade do processo de elaboração da legislação sobre as reformas no ensino, não se considerasse o sentido para o termo matéria tal como previsto na proposta inicial de reformulação curricular e que se compreendesse o termo disciplina em seu sentido tradicional.

A princípio, três matérias (comunicação e expressão, estudos sociais e ciências) organizariam o currículo em seu caráter macroestrutural e possuiriam o objetivo de constituir referência para a sistematização das atividades realizadas na escola, porém, em sua interpretação posterior, a noção de matéria se limitou a agrupar e denominar conjuntos de disciplinas.

Assim, a resolução CFE n. 8/71 associou cada uma das matérias a um conjunto de disciplinas obrigatórias: a matéria de estudos sociais incluía as disciplinas geografia, história e organização social e política do Brasil; a matéria de ciências incluía matemática e ciências físicas e biológicas.

Em relação à matéria de comunicação e expressão, a questão torna-se um pouco mais complexa, pois há diferentes apresentações em relação a sua constituição, a ponto de por vezes ela ser considerada equivalente à própria disciplina língua portuguesa.

Nesse sentido, mesmo no artigo de Silva e Arelano (idem) encontram-se diferenças em relação aos modos como são apresentadas as disciplinas que constituiriam a matéria em questão. Há, no texto, dois momentos em que aparecem os nomes das disciplinas obrigatórias: num deles, há apenas referência à disciplina língua portuguesa, que comporia como elemento único a matéria de comunicação e expressão. Em outro momento do artigo, quando é feita nova referência às disciplinas obrigatórias, aparecem, dessa vez, também as disciplinas educação fisicica e artes, porém, nessa passagem, as disciplinas são referidas sem que seja feita alusão ao fato de elas constituírem, em conjunto, uma matéria. 
Os Guias curriculares para o ensino de $1^{\circ}$ grau (São Paulo, 1975, p. 5), ${ }^{7}$ por sua vez, quando se referem à matéria de comunicação e expressão, nela incluem educação artística e educação física, o que parece indicar que tal matéria, segundo a perspectiva oficial, não se associaria, a ponto de se equivaler, à disciplina língua portuguesa:

\begin{abstract}
Descontinuidade dos "programas" referentes às matérias tradicionais somada à introdução de novos conteúdos curriculares, sem lastro histórico na organização escolar, decidiram a individualização dos detalhamentos das atividades de cada um dos conteúdos específicos das matérias (exceção feita a Estudos Sociais). Estruturados à base do currículo centralizado na matéria, são sete os guias propostos, como modelos de referência abrangendo o Núcleo Comum: três para Comunicação e Expressão-língua portuguesa, educação artística e educação fisica; três para Ciências - matemática, ciências e programa de saúde; um para Estudos Sociais, que, com o acréscimo da proposta referente à Formação Especial, constituem-se em subsídios para implantação da escola de $1^{\circ}$ grau.
\end{abstract}

Nota-se, na passagem transcrita, que a associação das disciplinas às matérias componentes do currículo apresenta diferenças para com a própria resolução CFE n. 8/71: estudos sociais são tratados como uma disciplina específica, e não como matéria que incorpora as disciplinas de geografia, história e organização social e politica do Brasil; e entre as disciplinas que compõem a matéria de ciências: em lugar de biologia há a referência a programa de saúde.

Percebe-se, assim, que houve diferentes modos de apropriação ${ }^{8}$ das propostas presentes no projeto de reestruturação curricular do ensino fundamental.

${ }^{7}$ Doravante denominados, neste trabalho, Guias curriculares.

${ }^{8}$ A noção de apropriação é compreendida, neste trabalho, conforme o sentido que lhe confere Chartier (1990, p. 136): para o autor, tal noção é útil "porque permite pensar as diferenças na divisão, porque postula a invenção criadora no próprio cerne dos processos de recepção". Uma abordagem que centra suas atenções na distribuição dos objetos culturais seria, então, substituída por outra que centrasse a sua atenção "nos empregos diferenciados, nos usos contrastantes dos mesmos bens, dos mesmos textos, das mesmas ideias".
A associação, em termos de equivalência, entre matéria de comunicação e expressão e disciplina língua portuguesa parece ser algo realizado exteriormente às instâncias oficiais e mesmo ao meio acadêmico, quando considerada sua contribuição para a elaboração dos Guias curriculares (idem).

Talvez a mudança na denominação e nos objetivos da disciplina língua portuguesa a que refere Soares (idem) se tenha realizado, de fato, na apropriação didática das propostas de reestruturação do ensino fundamental no país. Nesse sentido, a apropriação, pelos produtores de material didático, do que se propunha na lei n. 5.692/71 parece ter sofrido mais fortemente os efeitos da confusão semântica ocasionada pelas alterações nos significados tradicionalmente atribuídos aos termos matéria, área de conhecimento e disciplina.

\section{Os Guias curriculares para o ensino de $1^{\circ}$ grau no estado de São Paulo}

Os Guias curriculares, produzidos na década de 1970, tiveram sua publicação financiada com recursos da quota federal do salário-educação, com base no convênio MEC/DEF/FNDE de 1973.

Em sua carta de apresentação dos Guias curriculares, o então Secretário da Educação do Estado de São Paulo afirma a consonância do documento para com o texto da lei federal de reorganização do ensino fundamental, considerando-os o "primeiro esforço de estruturação de uma escola fundamental de oito anos de escolarização, dotada de atributos de unidade e continuidade", cujo objetivo seria consolidar "uma política educacional inspirada no princípio democrático de maior oportunidade para todos, já irreversível no Estado de São Paulo".

De acordo com seu texto introdutório, a elaboração dos Guias curriculares fez-se de modo que esses documentos não se constituíssem em modelos para reprodução em sala de aula, mas "como pontos de referência para o planejamento das atividades a ser elaborado pelo professor". Nesse mesmo sentido, a elaboração fez-se com base no princípio da colaboração de representantes de todos os graus do sistema de ensino, a fim de assegurar "uma visão do total processo 
escolar". O documento registra, então, a novidade de que "pela primeira vez um diálogo profundo estabelecia-se entre professores de todos os níveis".

Ainda em respeito ao que se encontra na lei n.5.692/71, os Guias curriculares (idem, "Considerações gerais”) propõem-se a ser adaptáveis a diferentes condições, que incluiriam as diversificações culturais, as diferenças individuais e a disponibilidade desigual de recursos materiais. O objetivo da flexibilidade seria oferecer ao professor a possibilidade de adaptar as propostas de ensino às circunstâncias que encontrasse em seu contexto de trabalho:

\footnotetext{
Organizadas e ordenadas, as proposições pretendem ser abrangedoras, isto é, buscam considerar todos os aspectos significativos da matéria, de modo que seus conteúdos venham a refletir o que se passa no mundo da cultura atual e atender às necessidades de organização humana. A multiplicidade de objetivos que se operacionalizam e de situações de experiências que se sugerem pode parecer pretensiosa. Todavia, têm propriedade: além de atender a uma escola que se quer a melhor, permite que as proposições ganhem outro atributo - a flexibilidade, isto é, são elas adaptáveis às condições particulares de localidade, de escola, de classe, de aluno. Em razão dessa multiplicidade, não se especificam proposições considerando diferenças devidas a sexo, condições econômico-culturais ou, mesmo, considerando diferentes condições físicas da escola, suas instalações e equipamentos ou da extensão da jornada diária.
}

Nas referências aos modos como é concebido o trabalho pedagógico e o processo de apropriação de conhecimentos com objetivos didáticos, nos Guias curriculares (idem), em sua Introdução, afirmam-se os cuidados por não se seduzir pela facilitação, pela rotina e pelo apego às teorias da moda:

Recolhem os conteúdos curriculares todas as experiências valiosas. Não se questionou a taxa de inovação ou conservação com que contribuem. O que se questionou foi a validade dos modelos propostos, com a preocupação de não mascarar soluções velhas com rótulos novos e a de não propor soluções apressadas e indefinidas e, por isto, falsas, para a qualquer título inovar.
Esse cuidado respondia a uma preocupação, já presente à época, em relação aos modos como as teorias e concepções científicas eram transpostas para os materiais didáticos, que, para se mostrarem modernos, faziam uso duvidoso ou inapropriado da produção acadêmica de conhecimentos.

Como se pode ler em suas "Considerações gerais", os Guias curriculares apresentam um conjunto de diretrizes provenientes de campos diversos de conhecimento, refletindo concepções distintas de sujeito, de linguagem, de ensino e de aprendizagem. Afirmase, nos documentos, que estes se fundamentam "nas generalizações das ciências pedagógicas e da filosofia" e pondera-se que "os conteúdos foram selecionados em função de seu valor instrumental, isto é, pela sua condição de recurso hábil em promover a formação da criança e do pré-adolescente".

Ao tratar de sua organização, os elaboradores dos Guias curriculares afirmam terem sido eles produzidos concebendo-se o ensino segundo uma ordem que previa um processo de estruturação que seguiria do mais simples para o mais complexo. Essa ordem diria respeito à aquisição de comportamentos que o aluno deveria apresentar ao final das oito séries: "ao se definirem os objetivos relativos às unidades, buscou-se hierarquizá-las de modo que a aquisição de comportamentos mais simples se situasse, na escala das séries, com anterioridade à aquisição de comportamentos mais complexos". Uma vez que as mudanças comportamentais se fizessem manifestas, poderiam ser, então, diretamente controláveis.

$\mathrm{O}$ ensino e a aprendizagem, fundamentados no que se denominava estruturação, far-se-iam com base na repetição, no treino, até que o aluno tivesse "captado inteiramente sua completa formulação sistemática".

Fundada em considerações de Jerome Bruner, ${ }^{9}$ a noção de currículo que se apresenta nas "Considerações gerais" propõe como objetivo do ensino e da aprendiza-

9 Não se apresenta bibliografia no documento em análise, mas, após a citação de palavras de Jerome Bruner (1968), é feita, na página 2 das "Considerações gerais", referência à obra $O$ processo da educação. 
gem a emancipação do sujeito e a construção de possibilidades para que este atue em seu contexto, consideradas as características culturais de sua comunidade.

Com base nas ideias desse autor, as propostas presentes nos Guias curriculares fundamentam seus objetivos em princípios que enfatizam o desenvolvimento de habilidades, da criatividade, da responsabilidade do aluno no seu próprio desenvolvimento, o que possibilitaria ao aluno chegar "a uma concepção clara da cultura de seu meio e da sua época", com base no "desenvolvimento gradativo de valores estéticos, morais, cívicos, econômicos e culturais".

Tais princípios, apoiados nas ideias de Bruner, como referido, concebem que o desenvolvimento possui uma base social, cultural, o que, para esse autor, constituiria a possibilidade da produção dos significados, e, portanto, da interpretação, da criação.

Termos como comunicação, informação, criatividade, que, consideradas as diversas instâncias em que foram empregados, apresentam forte polissemia no período em estudo, precisam ser compreendidos, portanto, no texto dos Guias curriculares, em consonância com uma concepção de linguagem e de conhecimento que prevê a função constitutiva do outro para a inserção no que é social, cultural.

Comunicação, no sentido que possui para a perspectiva da psicologia cultural de Bruner, refere-se à possibilidade de produção de significados, que ocorre sempre situada contextualmente como função da cultura e em dependência das relações com os outros sociais. Assim, segundo a perspectiva em questão, a informação em si mesma é desprovida de valor, na medida em que não possui sentido, não produz significado.

A concepção de criatividade, segundo tal compreensão do desenvolvimento, também precisa ser considerada em sua relação com a produção de significado, e, nesse contexto, como resultante do trabalho de interpretação dos sujeitos. A criatividade é compreendida em sua relação com o aprendizado do uso da linguagem, que implica apropriar-se da cultura e produzir significados que sejam apropriados à cultura. Como comenta Correia (2003, p. 511), em sua discussão das proposições de Bruner:
O significado dos conceitos sociais está no mundo, na negociação entre as pessoas; a própria cultura, que é um produto do uso da linguagem, precisa ser interpretada por quem participa dela. E a cultura é, ao mesmo tempo, um processo que está em constante recriação, através das interpretações e negociações de seus participantes. Assim, a linguagem não tem a função apenas de transmitir, ela cria realidades e consciência, fornece novos meios à cognição para investigar e explicar o mundo. A interpretação, a invenção e a revisão dos sistemas de símbolos estariam por trás de muitos dos nossos conhecimentos, ações, artes, ciências, do nosso mundo em geral, ou seja, os significados de tais sistemas dependem da cultura, ainda que possam usar os mesmos símbolos.

De acordo com as bases teóricas gerais dos Guias curriculares, noções como as de informação, comunicação e criatividade, ou mesmo comportamento e habilidade, são compreendidas em uma perspectiva construtivista, de base social, a partir de ideias da psicologia cultural. Desse modo, não se encontra, nas diretrizes curriculares para o período analisado, compreensão desses termos a partir dos preceitos da teoria da comunicação - que, de acordo com Soares (idem), teria prevalecido nesse momento histórico, ao menos em relação à disciplina língua portuguesa (ou, em sua outra denominação, à comunicação e expressão).

\section{O ensino de língua portuguesa na composição dos Guias curriculares}

As concepções de sujeito, de linguagem e de conhecimento que os Guias curriculares apresentam em sua parte introdutória geral diferem das que se encontram em sua seção destinada especificamente à língua portuguesa. Na parte introdutória aos Guias curriculares específicos de língua portuguesa, as perspectivas teóricas sobre linguagem são apresentadas como de caráter funcional, às quais se adicionam perspectivas de base racionalista, considerando-se os modos como concebida a associação de pensamento e linguagem.

Em relação ao caráter funcional da linguagem, lê-se no documento em análise: 
O guia que ora se apresenta baseia-se no caráter funcional da língua e está centrado no objetivo geral da matéria: desenvolver a habilidade de comunicar-se mais ampla e mais eficazmente nas diferentes situações de discurso:

Troca de informação;

Manifestação de emoções;

Manifestações volitivas etc. (São Paulo, 1975, p. 11)

Ainda que a referência à eficácia comunicativa na passagem citada seja compreendida no interior de perspectiva teórica de caráter funcional, a ideia de comunicação não se fundamenta simplesmente em noção de referência de base estruturalista, que considera que o valor dos signos se constitui em relações de oposição internas a um sistema. No parágrafo seguinte ao referido, torna-se claro que a noção de comunicação é compreendida com base em relação de interdependência entre língua e pensamento:

Língua e pensamento são conceitos inseparáveis, interdependentes. Enquanto se aprende língua, estrutura de língua, desenvolvem-se os esquemas mentais pela possibilidade de abstrair das coisas e do tempo que a língua permite. Processos e procedimentos linguísticos favorecem o pensamento e a sua organização. Não devemos esperar que um se realize primeiro: a partir do momento em que a criança adquire a linguagem, os dois se interinfluenciam. Daí a importância do ensino da língua para a simultânea evolução dos dois tipos de estrutura. O objetivo, pois, consiste fundamentalmente em favorecer a aquisição de comportamentos de língua e de pensamento e não apenas em informar. (idem, ibidem)

Temos assim, fundamentando os Guias curriculares para o ensino de língua portuguesa, uma noção de referência bastante sofisticada, que associa elementos próprios à perspectiva estrutural e à perspectiva racionalista: considerando as relativas autonomias da língua e do pensamento, concebidos enquanto estruturas, integra-os em um processo de desenvolvimento em que se relacionam constitutivamente. ${ }^{10}$ É nesse contexto teó-

${ }^{10}$ A presença de ideias elaboradas pelo professor Carlos rico que se compreendem termos como comportamento, comunicação, informação ou modelo.

Assim, como também visto em suas "Considerações gerais", não há, nas concepções de ensino e de aprendizagem que fundamentam os Guias curriculares, a prevalência de concepções de linguagem fundamentadas na teoria da comunicação.

Encontra-se, nos Guias curriculares, uma relação polêmica ${ }^{11}$ com base na contraposição entre os conhecimentos gramaticais normativos tradicionais e os conhecimentos gramaticais elaborados pelos estudos linguísticos modernos. Segundo os documentos em análise, as propostas de mudanças no ensino de língua portuguesa seriam obtidas em função da aquisição, por parte dos professores, dos conhecimentos oferecidos pela linguística:

Se encontramos de um lado a minoria de professores de língua portuguesa que tenta mudar procedimentos didáticos fundamentados em contribuições da linguística, vemos por outro lado uma grande maioria insatisfeita, às vezes amedrontada com mudanças que são urgentes e necessárias. A formação para ensino de línguas que receberam baseava-se em conceitos, hoje, superados diante dos progressos da linguística, conceitos que necessitam de reformulação para se atingirem os objetivos reais do ensino da língua materna. Isso tem entravado a evolução do ensino de nossa língua na escola de $1^{\circ}$ grau a ponto de nos depararmos com a situação insustentável da atualidade. (idem, ibidem)

Na sequência do texto, apresentam-se algumas causas de tal situação, como a crítica ao ensino fundamentado na gramática normativa tomada como fim e a

Franchi é evidente se consideradas as concepções de linguagem e os termos utilizados para expressá-la. Nos Guias curriculares, ao final da relação de nomes que compuseram a equipe elaboradora da parte referente ao ensino de língua portuguesa, há menção destacada à colaboração especial do professor Carlos Franchi.

${ }^{11}$ Como já referido, o termo polêmica é compreendido aqui de acordo com a noção de interdiscurso proposta por Maingueneau (2005). 
ausência, na escola, de conhecimentos científicos sobre linguagem e sobre os objetivos de se ensinar língua.

A noção de gramática considerada interessante nos Guias curriculares parte do princípio de que o aluno é um "competente falante de sua língua nativa", o que propõe a necessidade de alterar o ensino fundamentado nas concepções próprias à gramática normativa tradicional:

\footnotetext{
Neste trabalho, gramática é a explicitação dos conhecimentos que o falante nativo tem a respeito do funcionamento da sua língua.

Nesse sentido gramática é diferente da tradicional gramática normativa que ditava regras prescritivas para o uso erudito da língua. Decorre, daí que o papel da gramática é tornar o falante consciente do sistema de transformações que os modelos sofrem para atingir um grau de aceitabilidade dentro da língua. Partindo de sua própria linguagem o aluno será levado a reconhecer e utilizar formas características de outros registros (por exemplo, o do professor). Este papel da gramática está ligado ao desenvolvimento mental e aos processos de equilibração e nos dá maior possibilidade de compreender o processo de contínuo desenvolvimento linguístico de um falante. (idem, p. 12)
}

Nesse sentido, o ensino de língua portuguesa partiria do princípio de que a língua se define por sua estrutura, e ensinar língua consistiria, então, em realizar

[...] exercícios de língua (exercícios estruturais, de análise, de síntese, de classificação, de relacionamento, de transformações), para que o aluno se habilite a usar a língua para produção e compreensão de frases, na medida em que consegue variedade e complexidade de estruturas e amplia suas possibilidades de escolha e seleção ao comunicar-se. (idem, ibidem)

O ensino de língua portuguesa não se faria, portanto, com base na apropriação, por parte do aluno, de metalinguagem própria ao conhecimento gramatical tradicional, mas se fundamentaria no trabalho com a linguagem. Como é afirmado no documento em análise, "não é a gramática normativa que ensina língua, mas sim a própria língua”. Encontra-se, desse modo, um deslocamento em relação às concepções de língua e gramática que fundamentam posturas prescritivas, as quais destruiriam a livre-expressão do aluno.

Há, portanto, uma nova concepção de gramática proposta pelos Guias curriculares, concepção que se contrapõe à gramática normativa tradicional e aos seus usos escolares. As práticas de ensino, em consonância com essa nova concepção, deveriam também ser alteradas, a fim de privilegiar as atividades linguísticas e não o trabalho com metalinguagem.

Nesse sentido, é necessário reconsiderar a ideia de que haveria um hiato, em relação ao ensino de gramática na escola, no momento histórico observado. Segundo Soares (idem), a gramática normativa tradicional teria deixado de ser, no período em questão, a base do ensino de lingua portuguesa na escola, que passaria a se fundamentar, como referido, em elementos próprios à teoria da comunicação.

Ainda que a ausência da gramática (ou ao menos a diminuição de sua importância) possa ser algo constatado em outras instâncias, como as de elaboração de materiais didáticos, o mesmo não se pode constatar nas propostas curriculares para o ensino de língua portuguesa no estado de São Paulo. Nesses documentos, que são elaborados com base em conhecimentos produzidos na academia, a gramática é tomada como referência para o ensino de língua materna.

Essa referência pode ser compreendida de duas maneiras: ou em relação à contraposição entre a gramática normativa tradicional e a gramática fundamentada nos estudos linguísticos modernos; ou em relação ao fato de os conhecimentos gramaticais tradicionais serem tomados não mais como finalidade do ensino, mas como meio para possibilitar ao aluno desenvolver sua competência comunicativa. Tanto num caso como no outro, não é a ausência da gramática, mas a presença de uma nova concepção de gramática, em situação de relação polêmica para com a normativa tradicional, 
que fundamenta as propostas curriculares para o ensino de língua portuguesa como língua materna.

\section{Considerações finais}

As alterações na disciplina curricular de língua portuguesa na década de 1970 do século XX, no Brasil, fazem-se em função de fatores diversos, específicos das diferentes instâncias em que o processo de constituição da disciplina se realizou.

Nesse contexto histórico, encontra-se um conjunto heterogêneo de concepções de língua portuguesa e de seu ensino em que concorrem saberes gramaticais tradicionais, saberes produzidos pelos estudos linguísticos e ideias elaboradas em conformidade com a teoria da comunicação.

Como visto, essa heterogeneidade parece ser resultante das diferentes interpretações realizadas do texto da lei n. 5.692/71, que altera não apenas a estrutura curricular do ensino fundamental, mas a própria concepção de ensino e de aprendizagem, ressignificando termos como disciplina, matéria érrea de estudos, o que levou a considerar-se de modos diversos, em diferentes instâncias, a constituição da disciplina língua portuguesa, inclusive em relação à sua denominação.

Se em determinadas instâncias, como as produtoras de material didático, se compreendeu que a disciplina passava a ser denominada comunicação $e$ expressão e que seus objetivos eram função da proposta pragmatista de ensino de língua estabelecida pelo regime militar, em outras instâncias, como a acadêmica ou mesmo a oficial - considerando-se a relação que estabelece com os conhecimentos elaborados na academia -, a compreensão da organização curricular e dos objetivos do ensino de língua portuguesa fez-se em função de perspectiva construtivista, de base cultural, sobre ensino e aprendizagem, e de perspectiva funcionalista de linguagem.

Nesse sentido, se houve, como afirma Soares (idem), um hiato em relação ao ensino de gramática em determinadas instâncias, não se percebe esse hiato nos documentos oficiais sobre ensino de língua portuguesa e nas instâncias acadêmicas que colaboraram para a elaboração dos Guias curriculares de São Paulo.
Fundamentados em ideias linguísticas, havia já nesses documentos a polêmica entre linguística e gramática que vai consolidar-se na década seguinte e que se mantém atual em produções que defendem a necessidade de mudanças no ensino de língua portuguesa.

Os resultados da análise dos documentos de referência curricular elaborados no período histórico observado mostram também que, mesmo em espaços institucionais responsáveis por garantir maior controle dos sentidos, dado o objetivo do estado de regular o processo escolar de saberes e práticas, a produção dos sentidos se faz com base em relações interdiscursivas fundadas em polêmica.

A elaboração de documentos de referência curricular parece não se fazer, portanto, com a transposição didática de conhecimentos produzidos nas ciências de referência, mas segundo regras próprias de produção discursiva. Assim, compreender o processo de escolarização em suas especificidades parece ser produtivo também para considerar as práticas discursivas que se desenvolvem externamente à escola, mas com o objetivo de produzir efeitos sobre ela. Os documentos de referência curricular não se constituiriam, então, como um produto, algo pronto, a produzir efeitos a serem controlados em decorrência mesmo do caráter prescritivo de tais instrumentos. Talvez seja mais interessante considerá-los em função de suas condições de produção, dos saberes e práticas que se produzem nesse espaço heterogêneo que envolve relações entre elementos próprios ao acadêmico, ao oficial, ao pedagógico.

Os documentos de referência curricular podem funcionar tanto para o controle dos sentidos quanto para a produção de efeitos de sentido imprevistos, segundo relações interdiscursivas não anteriormente consideradas. Possibilitam inventar uma tradição que pode caracterizar-se não apenas pela homogeneidade ou pela tentativa de reprodução de um sentido único que construísse filiação com o passado mas pelo seu direcionamento para o futuro, ao fundar-se na ideia da necessidade da inovação. Paradoxalmente, esse processo pode levar a que se constitua uma nova tradição, caracterizada pela repetição da polêmica em que se fundamenta: da crítica ao tradicional e da afirmação de que é preciso modernizar. 


\section{Referências bibliográficas}

BITTENCOURT, Circe M. F. Disciplinas escolares: história e pesquisa. In: OLIVEIRA, Marcus Aurélio T. de; RANZI, Serlei M. F. (Orgs.). História das disciplinas escolares no Brasil: contribuições para o debate. Bragança Paulista: EDUSF, 2003.

BRUNER, Jerome. O processo da educação. Trad. Lólio Lourenço de Oliveira. São Paulo: Nacional, 1968 (3. ed. 1972).

CHARTIER, Roger. A história cultural: entre práticas e representações. Trad. Maria Manuela Galhardo. Lisboa: DIFEL, 1990.

CHERVEL, André. História das disciplinas escolares: reflexões sobre um campo de pesquisa. Teoria e Educação, Porto Alegre, n. 2, p. 177-229, 1990.

CHEVALLARD, Yves. La transposition didactique: du savoir savant au savoir enseigné. Grenoble: La Pensée Sauvage, 1985 (2. ed. 1991).

CORREIA, Mônica F. B. A constituição social da mente: (re) descobrindo Jerome Bruner e construção de significados. Estudos de Psicologia, v. 8, n. 3, p. 505-513, set./dez. 2003.

GATTI JR., Décio. A escrita brasileira recente no âmbito de uma história das disciplinas escolares (1990-2008). Currículo sem Fronteiras, v. 9, n. 1, p. 42-71, jan./jun. 2009.

GOODSON, Ivor. Currículo: teoria e história. 7. ed. Trad. Attílio Brunetta. Petrópolis: Vozes, 2005.

As políticas de currículo e de escolarização: abordagens históricas. Trad. Vera Joscelyne. Petrópolis: Vozes, 2006.

HOBSBAWM, Eric. J.; RANGER, Terence (Orgs.). A invenção das tradições. Rio de Janeiro: Paz e Terra, 1984.

MAINGUENEAU, Dominique. Novas tendências em análise do discurso. Trad. Freda Indursky. Campinas: Pontes/Editora da Unicamp, 1989.
MAINGUENEAU, Dominique. Gênese dos discursos. Trad. Sírio Possenti. Curitiba: Criar, 2005.

SÃO PAULO. Secretaria da Educação. Guias curriculares para o ensino de $1^{\circ}$ grau. São Paulo: CERHUPE, 1975.

SILVA, Tereza R. N.; ARELANO, Lisete R. G. Orientações legais na área de currículo, nas esferas federal e estadual a partir da Lei 5.692/71. Cadernos Cedes, v. 1, n. 13, p. 26-44, jan. 1985.

SOARES, Magda. Português na escola - História de uma disciplina curricular. In: BAGNO, Marcos (Org.). Linguística da norma. São Paulo: Loyola, 2002.

SOUZA JÚNIOR, Marcílio; GALVÃO, Ana Maria de O. História das disciplinas escolares e história da educação: algumas reflexões. Educação e Pesquisa, v. 31, n. 3, p. 391-408, set./dez. 2005.

ÉMERSON DE PIETRI, doutor em linguística aplicada, é professor da Faculdade de Educação da Universidade de São Paulo, atuando na área de Metodologia do Ensino de Língua Portuguesa. Publicações recentes: Circulação de saberes e mediação institucional em documentos oficiais: análise de uma proposta curricular para o ensino de língua portuguesa (Currículo sem Fronteiras, v. 7, n. 1, p. 263-283, jan./jun. 2007); A constituição da escrita escolar em objeto de análise dos estudos linguísticos (Trabalhos em Linguística Aplicada, v. 46, n. 2, p. 283-297, jul./dez. 2007); Concepções de linguagem e ensino da escrita em materiais didáticos (Estudos Linguísticos, v. 37 , n. 2, p. 37-46, maio/ago. 2008). Pesquisa em andamento: "Escrita escolar: saberes acadêmicos, propostas oficiais de ensino e elaboração de materiais didáticos”.E-mail: pietri@usp.br

Recebido em abril de 2009 Aprovado em dezembro de 2009 
Émerson de Pietri

\section{Sobre a constituição da disciplina curricular de língua portuguesa}

O objetivo deste artigo foi considerar mais detalhadamente um momento do processo histórico de constituição da disciplina curricular língua portuguesa no Brasil. Na década de 1970, alterouse a organização da escolarização básica e instâncias oficiais responsáveis pelo ensino publicaram documentos que subsidiavam, teórica e metodologicamente, as mudanças curriculares propostas. Fundamentada em perspectiva discursiva, a análise de documentos produzidos no período revela características importantes a respeito dos modos de apropriação, com objetivos pedagógicos, de saberes acadêmicos sobre linguagem. A análise possibilitou também evidenciar a complexidade desse momento histórico, caracterizado pela diversidade de aspectos acadêmicos, políticos e didáticos em concorrência.

Palavras-chave: ensino de língua portuguesa; currículo; história das disciplinas.

\section{On the constitution of Portuguese as} a curriculum subject

This paper considers a moment in the historical process of the constitution of Portuguese as a curricular discipline in Brazil. In the 70s of the twentieth century, changes were carried out in the structure of the educational system. The authorities responsible for the educational system produced documents to subsidize, theoretically and methodologically, the curricular changes proposed. Discursive analysis of these documents reveals important characteristics about the modes of appropriation, with didactic objectives, of academic knowledge about language. The analysis also provides evidence that the referred moment is characterized by concurrent conceptions of knowledge, public policy and language teaching.

Key words: teaching of the Portuguese language; curriculum; history of school subjects.

\section{Sobre la constitución de la disciplina} curricular de la lengua portuguesa

Este artículo tiene como objetivo considerar más detalladamente un momento del proceso histórico de constitución de la disciplina curricular Lengua Portuguesa en Brasil. En la década de 1970, fue alterada la organización de la escolarización básica e instancias oficiales responsables por la enseñanza publicaron documentos que subsidiaban, teórica y metodológicamente, los cambios curriculares propuestos. Fundamentada en la perspectiva discursiva, los documentos producidos en el periodo, fueron analizados y revelaron importantes características con respecto a los modos de apropiación., con objetivos pedagógicos, del saber académico sobre lenguaje. El análisis también posibilitó la muestra de la complejidad de ese momento histórico, caracterizado por la diversidad de aspectos académicos, políticos y didácticos en concurrencia. Palabras claves: enseñanza de la lengua portuguesa; currículo; historia de las disciplinas. 